\title{
Comparison between swallowing and chewing of garlic on levels of serum lipids, cyclosporine, creatinine and lipid peroxidation in Renal Transplant Recipients
}

\author{
Abbas Jabbari ${ }^{1}$, Hassan Argani ${ }^{* 2}$, Amir Ghorbanihaghjo ${ }^{3}$ and Reza Mahdavi ${ }^{4}$
}

Address: ${ }^{1}$ Clinical pharmacy laboratory, Drug Applied Research Center, Tabriz University of Medical Sciences, University Ave., Tabriz, Iran, ${ }^{2}$ Clinical pharmacy laboratory, Drug Applied Research Center, Tabriz University of Medical Sciences, University Ave., Tabriz, Iran, ${ }^{3}$ Biochemistry and Drug Metabolism Laboratory, Drug Applied Research Center, Tabriz University of Medical Sciences,, University Ave., Tabriz, Iran and ${ }^{4}$ Nutrition Laboratory, Drug Applied Research Center, Tabriz University of Medical Sciences, University Ave., Tabriz, Iran

Email: Abbas Jabbari - abbasjabbari@yahoo.com; Hassan Argani* - hassanargani@hotmail.com; Amir Ghorbanihaghjo - ghorbaniamir@hotmail.com; Reza Mahdavi - mahdavirez@hotmail.com

* Corresponding author

Published: 19 May 2005

Lipids in Health and Disease 2005, 4:II doi:10.1186/1476-5IIX-4-II

This article is available from: http://www.lipidworld.com/content/4/I/II

(C) 2005 Jabbari et al; licensee BioMed Central Ltd.

This is an Open Access article distributed under the terms of the Creative Commons Attribution License (http://creativecommons.org/licenses/by/2.0), which permits unrestricted use, distribution, and reproduction in any medium, provided the original work is properly cited.
Received: 0I March 2005

Accepted: 19 May 2005

\begin{abstract}
Abstract Hyperlipidemia and increased degree of oxidative stress are among the important risk factors for Atherosclerosis in renal transplant recipients (RTR). The Medical treatment of hyperlipidemia in RTR because of drugs side effects has been problematic, therefore alternative methods such as using of Garlic as an effective material in cholesterol lowering and inhibition of LDL Oxidation has been noted. For evaluation of garlic effect on RTR, 50 renal transplant patients with stable renal function were selected and divided into 2 groups. They took one clove of garlic (I gr) by chewing or swallowing for two months, after one month wash-out period, they took garlic by the other route. Results indicated that although lipid profile, BUN, Cr, serum levels of cyclosporine and diastolic blood pressure did not change, Systolic blood pressure decreased from 138.2 to $132.8 \mathrm{mmHg}(\mathrm{p}=0.00 \mathrm{I})$ and Malondialdehyde (MDA) decreased from 2.4 tol.7 nmol $/ \mathrm{ml} \quad(p=0.009)$ by swallowing route, Cholesterol decreased from 205.1 to 195.3 $\mathrm{mg} / \mathrm{dl} \quad(p=0.03)$, triglyceride decreased from 195.7 to $174.8 \mathrm{mg} / \mathrm{dl} \quad(p=0.008)$, MDA decreased from 2.5 to $\mathrm{I} .6 \mathrm{nmol} / \mathrm{ml}(p=0.00 \mathrm{I})$, systolic blood pressure decreased from I 37.5 to $129.8 \mathrm{mmHg}$ $(p=0.00 \mathrm{I})$, diastolic blood pressure decreased from 84.6 to $77.6 \mathrm{mmHg}(p=0.00 \mathrm{I})$ and $\mathrm{Cr}$ decreased from $1.5 \mathrm{I}$ to $1.44 \mathrm{mg} / \mathrm{dl}(p=0.03)$ by chewing route too. However HDL, LDL and cyclosporine serum levels had no significant differences by both of swallowing and chewing routes. We conclude that undamaged garlic (swallowed) had no lowering effect on lipid level of serum. But Crushed garlic (chewed) reduces cholesterol, triglyceride, MDA and blood pressure. Additionally creatinine reduced without notable decrease in cyclosporine serum levels may be due to cyclosporine nephrotoxicity ameliorating effect of garlic.
\end{abstract}

\section{Introduction}

Cardiovascular disease (CVD) is the main cause of morbidity and mortality in renal transplant recipients [1] and it accounts for about $40 \%$ of deaths in this group of patients [2]. Several risk factors for CVD, such as lipid abnormalities and insulin resistance, may partly explain the accelerated development of atherosclerosis following renal transplantation [1]. In atherogenesis process, mac- 
rophages oxidate LDL and produce foam cells by OX-LDL that are characteristic for atherosclerosis [3]. Lipoprotein abnormalities are common in renal disease [4] these are reported in $50-80 \%$ of renal transplant recipients [5].

Pathogenesis of hyperlipidemia in Renal transplant recipients (RTR) is not fully understood, but dosage of steroid, consumption of cyclosporine, anti-hypertensive medication, rising of serum creatinine, proteinuria and diabetes mellitus have been considered [2].

There is increased degree of oxidative stress in RTR [6]. In these patients following hyperlipidemia and lipoprotein abnormalities, free radicals produced. Also immunosuppressive drugs can induce photosensitization reactions. These reactions lead to production of free radicals and aggravate lipid peroxidation [7].

The medical treatment of hyperlipidemia in transplant recipients is problematic [2]. Bile binding resins interfere with cyclosporine absorption and also lead to hyper triglyceridemia. Nicotinic acid causes hyperglycemia and rising of uric acid. Fibric acids cause myopathy, dyspepsia, gall bladder stones and rises of creatinine. Statins can induce hepatotoxicity, myopathy rhabdomyolysis (Especially if accompanied with cyclosporine) $[2,4,5]$. So alternative methods are deserved importance.

Garlic has been used for centuries as an herbal medicine in treating abscesses, cough, poisoning, parasites, worms, digestive and circulatory problems, snake bites [8] hemorrhoids, abdominal pain, loss of appetite and pneumonia [9]. Epidemiologic studies suggest that consumption of garlic may protect against carcinogenesis. In particular, the development of gastric and colorectal cancers seems to be prevented by alliums consumption [10,11]. Also garlic was known as an effective material in decreasing of blood pressure [12] and cholesterol $[13,14]$ also can inhibit LDL oxidation [15-17], platelet aggregation and adhesion $[18,19]$ and can increase Nitric oxide production [20]. Because of these beneficial effects of garlic, we decided to study the effect of garlic on lipid profile, lipid peroxidation and cyclosporine serum level and because of its irritant odor in chewing we chose two routes of swallowing and chewing for comparing of their efficacy.

\section{Method and materials}

50 renal transplant recipients with stable renal function (based on serum $\mathrm{Cr}<1.8 \mathrm{mg} / \mathrm{dl}$ ) were selected randomly (hyperlipidemic and normolipidemic) (Table 1)(see additional file 1, Table1, word). Patients had been transplanted more than 1 year and were treating with triple immunosuppressive regimen including of: cyclosporine, prednisolone and azathioprine / or mycophenolate mofetil. Some of patients were under hypolipemic agents and antihypertensive drugs. Drug regimen did not change in 2 months period before and during the study.

We divided patients into 2 groups randomly (A, B). Group A patients took one clove of raw aged garlic ( 1 gr) by swallowing and group $\mathrm{B}$ patients by chewing the same amount. At the start of study we checked their dietary regimen including of: intake of calorie, total fat (TF), saturated fatty acids (SFA), monounsaturated fatty acids (MUFA), polyunsaturated fatty acids (PUFA) and cholesterol. We checked also some clinical and Para clinical parameters including of: blood pressure, weight, triglyceride (TG), cholesterol (Chol), low density lipoprotein (LDL), high density lipoprotein (HDL), serum malondialdehyde (MDA), blood urea nitrogen (BUN), creatinine (Cr) and cyclosporine serum level. Patients took garlic for 2 months then we checked above parameters again. After one month wash-out period the patients took garlic by the other route (swallowing changed to chewing and vice versa) with the same condition (as a cross over design).

Lipid profiles (TG, Chol, LDL, HDL), BUN and Cr were measured by standard enzymatic method, MDA determined by colorimetric method using thiobarbituric acid reactions [21] and cyclosporine serum level measured by RIA.

Data were analyzed by paired sample t test and Non parametric 2 related sample test using SPSS11.5 program. A difference was considered statistically significant when the $P$ value was $<0.05$.

\section{Results}

In this study 2 patient (group A) because of heart burn, 1 patient (group A) because of bloating, 3 patients because of change in drug regimen were excluded (group B) 44 patients continued the study (22 patients in each group).

In patients who swallowed garlic, weight, intake of calorie, SFA, MUFA, PUFA had no significant differences but intake of TF and Chol were increased during the study as compared with the pre garlic period. In patients who chewed garlic, weight, intake of calorie did not change however intake of TF, SFA, MUFA, PUFA and Chol increased during the study (table 2) (see additional file 2, Table 2, word).

Comparison between results of Chewing and Swallowing of garlic indicate that there is significant differences in diastolic blood pressure $(\mathrm{P}=0.016)$, triglyceride $(\mathrm{P}=$ $0.008)$ and cholesterol $(P=0.04)$ but not in systolic blood pressure $(P=0.187)$, HDL $(P=0.925)$, LDL $(P=0.354)$, MDA $(P=0.587)$, BUN $(P=0.657), C r(P=0.119)$ and cyclosporine serum level $(P=0.155)$. Other data are provided in table3 (see additional file 3, Table3, word). 


\section{Conclusion}

Several factors after transplantation produce hyperlipidemia include: weight gain and increase body fat mass due to appetite improvement [22].

Lopes et al reported that moderate energy restriction of about $30 \%$ and reducing fat in diet decreased cholesterol and LDL [23] however in our study dietary intake not only did not decreased but it increased significantly.

Adler and holub showed that LDL were reduced (14.2\%) and total cholesterol were significantly lower $(11.5 \%)$ with taking $900 \mathrm{mg}$ garlic/day for 12 weeks in hypercholesterolemic men [24].

Tohidi and Rahbani showed that taking $1200 \mathrm{mg}$ garlic powder for 4 weeks reduced total cholesterol $(9 \%)$, triglyceride (11\%), LDL (15\%), systolic blood pressure (3\%) and diastolic blood pressure (2\%) [15].

Steiner et al with giving 7.2 gr aged garlic extract (AGE) for 4 weeks indicated reduction in cholesterol (6.1\%), LDL (4\%), systolic and diastolic blood pressure (5.5\%) [14].

Issacsohn et al reported that taking $900 \mathrm{mg}$ garlic powder for 12 week did not change in lipid profile [8].

Mader showed that taking $800 \mathrm{mg}$ garlic powder for 4 months reduced cholesterol (9\%) and triglyceride (15\%) [25].

Lash et al reported that taking garlic tablets at a dose of $680 \mathrm{mg}$ two times a day for 6,12 weeks decreased LDL $(6 \%)$ and total cholesterol (4\%) significantly in hypercholesterolemic renal transplant patients [2].

Brinker mentioned that Effectiveness might be decreased by garlic's ability to induce metabolism and decrease levels of drugs like cyclosporine which are substrates of cytochrome P450 3A4. It can potentially cause transplant rejection [26].

Blech et al showed progression of atherosclerosis is relevant with oxidative stress and indicated with measurement of MDA [27].

MDA is important marker of lipid peroxidation [28] and reported that serum MDA decreased by antioxidants consumption [29].

In this study after chewing of garlic, systolic and diastolic blood pressure decreased 5\%, 8\%, like as Steiner and Tohidi studies. Also cholesterol and triglyceride reduced $4 \%, 10 \%$, according to Mader and Tohidi studies but less than these studies. Decreased Cholesterol in this study was like as Lash study however he did not report triglyceride reduction after garlic consumption. HDL did not change in all studies. Cyclosporine serum level decreased not significantly in our study and as we known it is the first study which demonstrated the effect of garlic on cyclosporine level in RTR.

Ingestion of garlic by chewing (or crushed garlic) can reduce cholesterol, triglyceride, MDA, systolic and diastolic blood pressure even in the presence of increasing fat intake. But undamaged garlic (swallowed) had no significant effect on serum lipids (TG, Chol, LDL and HDL), diastolic blood pressure, and BUN, $\mathrm{Cr}$ and cyclosporine serum level. Our hypothesis is that it is because of inability of Alliin to convert to Allicin. So the specific garlic odor is a hallmark of releasing of Allicin.

Acute cyclosporine nephrotoxicity is predominantly functional in that it produces no particular histological features. It is probably the result of renal arteriolar constriction, a feature that has been demonstrated in animals. In chronic cyclosporine nephrotoxicity the principal injury is to the small arterioles where there is vacuolation of smooth muscle and endothelial cells [30].

Reducing creatinine without notable decrease in cyclosporine serum level by chewing of garlic may be cyclosporine nephrotoxicity protecting effect of garlic as its effect on gentamycin nephrotoxicity due to its antioxidant effect [31] or calcium channel blockers like effects [32] or nitric oxide increasing vasodilatations [20].

Additional studies are necessary in order to investigate effect of garlic on cyclosporine serum levels, nephrotoxicity and serum creatinine.

In conclusion we found that crushed garlic (chewed) reduced total cholesterol, triglyceride, MDA (lipid peroxidation) and blood pressure that have important role in cardiovascular disease. Therefore garlic consumption can prevent this disease.

\section{Additional material}

\section{Additional File 1}

Table 1

Click here for file

[http://www.biomedcentral.com/content/supplementary/1476-

511X-4-11-S1.doc]

\section{Additional File 2}

Table 2

Click here for file

[http://www.biomedcentral.com/content/supplementary/1476-

511X-4-11-S2.doc] 


\section{Additional File 3}

\section{Table 3}

Click here for file

[http://www.biomedcentral.com/content/supplementary/1476511X-4-11-S3.doc]

\section{References}

I. Emilio R, Domingo Gonzalez L, Juan Carlos R, Gema Fernandez F, Debora I, Julio Gonzalez C, et al.: Apolipoprotein C-III and E Polymorphisms and Cardiovascular Syndrome, Hyperlipidemia, and Insulin Resistance in Renal Transplantation. Am J Transplantation 2002, 2:343-348.

2. Lash JP, Cardoso LR, Mesler PM, Walczak DA, Pollak R: The Effect of Garlic on Hypercholesterolemia in Renal Transplant Patients. Transp proce 1998, 30:189-191.

3. Porek C, Crawford D: Molecular mechanisms of oxidant induced transformation. In Active oxygen's, lipid peroxides and antioxidants Ist edition. Edited by: Yagi K. Scientific societies press, Japan; 1993:189-194.

4. McKay DB, Milford EL, Tolkoff NE, Rubin : Clinical Aspects of Renal Transplantation. In The Kidney Volume 2.6th edition. Edited by: Brenner BM, Levine SA. WB Saunders, USA; 2000:2584.

5. Braun WE: The Medical Management of Renal Transplant Recipient. In Comprehensive Clinical Nephrology 2nd edition. Edited by: Johnson RJ, Feehally J. Mosby, Spain; 2004: I 109-10.

6. Simic-Ogrizovic S, Simic T, Reljic Z, Blagojevic R, Radivojevic D, Lezaic $\checkmark$, et al:: Markers of Oxidative Stress after renal transplantation. Transpl Int 1998, I I:I25- I 29.

7. Jhan K, Belign M, McClean F: A Pharmacist's guide to cholesterol issues. NARD Journal 1991:37-45.

8. Isaacsohn JL, Moser M, Stein EA, Dudley K, Davey JA, Liskov E, Black HR: Garlic Powder and Plasma Lipids and Lipoproteins. Arch Intern Med 1998, I 58: I I89-I I 94.

9. Aouadi R, Aouidet A, Elkadhi A, Ben Rayana C, Jaafoura H, Tritar B, Nagati K: Effect of Fresh Garlic (Allium Sativum) on Lipid Metabolism in Male Rates. Nutrition Res 2000, 20:273-280.

10. Agarwal KC: Therapeutic actions of garlic constituents. Med Res Rev 1996, 16(I): I I I-24. Review

11. Dorant E, van den Brandt PA, Goldbohm RA: A prospective cohort study on the relationship between onion and leek consumption, garlic supplement use and the risk of colorectal carcinoma in The Netherlands. Carcinogenesis 1996, I 7(3):477-84.

12. Silagy CA, Neil HAW: A Meta - analysis of the effect of garlic on blood pressure. J Hypertens 1994, 1 2:463-468.

13. Stevinson C, Pittler H, Edzard E: Garlic for Treating Hypercholesterolemia. Ann Intern Med 2000, 133:420-429.

14. Steiner M, Khan AH, Holbert D, Lin RI: A double-blind crossover study in moderately hypercholesterolemic men that that compared the effect of aged garlic extract and placebo administration on blood lipids. Am J Clin Nutr 1996, 64:866-870.

15. Tohidi $m$, Rahbani m: Evaluation of the effect of garlic powder on blood pressure, serum lipids and lipoproteins. Pharmacy journal of Tabriz Univ Med Sci 2000, 4:16-20.

16. Mikhin VP, Gormnatskii NI: The effect of Garlic preparation alisat on the level of Lipid peroxidation Products. Activity of various antioxidant enzymes and blood levels of lipoproteins in patients with atherosclerosis. Ball-EK sp-Biol-med 1996, 1 229:502-504.

17. Heiner K, Thomas S: Effect of a Garlic oil preparation on serum lipoproteins and cholesterol metabolism. JAMA 1998, 279(23): 1900-1904.

18. Rahman K, Billington D: Dietary Supplementation with Aged Garlic Extract Inhibits ADP-Induced Platelet Aggregation in Humans. J Nutr 2000, 130:2662-2665.

19. Steiner M, Li W: Aged Garlic Extract, a Modulator of Cardiovascular Risk Factors: A Dose- Finding Study on the Effects of AGE on Platelet Functions. J Nutr 200 I, I 3 I (3s):980S-984S.

20. Morihara N, Sumioka I, Moriguchi T, Uda N, Kyo E: Aged Garlic Extract enhances production of nitric oxide. Life Sci 2002, $7 I(5): 509-5 I 7$.
21. Yagi K: Lipid peroxides and related radicals in clinical medicine. In Free Radicals in Diagnostic Medicine Ist edition. Plenum Press, New York; 1994:I- 15.

22. Appel G: Lipid abnormalities in renal disease. Kidney Int |99|, 39:169.

23. Lopes IM, Martin M, Errasti P, Martinez JA: Benefits of a dietary intervention on weight loss, body composition, and lipid profile after renal transplantation. Nutrition 1999, I5(I):7-10.

24. Adler AJ, Holub B]: Effect of garlic and fish-oil supplementation on serum lipid and lipoprotein concentrations in hypercholesterolemic men. Am J Clin Nutr 1997, 65:445-450.

25. Mader FH: Treatment of hyperlipidemia with garlic-powder tablets: evidence from the German Association of General Practitioner's multicentric placebo-controlled double-blind study. Arzneimittel Forschung Drug Re 1990, 40:3-8.

26. Brinker F: Herb Contraindications and Drug interactions. 2nd edition. Sandy (OR), Eclectic Med Publications; 1998: 105.

27. Belch JJ, Mackay IR, Hill A, Jening SP: Oxidative stress is present in atherosclerotic peripheral arterial disease and further increased by diabetes mellitus. Int-Angiol 1995, 14(4):385

28. Raharjo S, Sofos JN, Schmitt GR: Solid phase acid extraction improves thiobarbituric acid methods to determine lipid oxidation. J Food Sci 1993, 58:921-932.

29. Eander RC: Tocopherol influences in vivo induce of lipid peroxidation in post menopausal woman given fish oil. J Nutr 1996, I 26:643-652.

30. Salaman J, Feduska N, Fabre JW: Renal transplantation. In clinical atlas of the kidney Ist edition. Edited by: Williams JD, Asscher AW, Moffat DB, Sanders E. Lippincott, Singapore; 1991:14.27-14.28.

31. Perdaza Chaverri J, Maldonado PD, Medina-Campos ON, OlivaresCorichi IM, Granados-Silvestre MLA, Hernandez-Pando R, IburaRubio ME: Garlic ameliorates Gentamycin Nephrotoxicity: Relation to antioxidant enzymes. Free Radical Biology and Medicine 2000, 29(7):602-6II.

32. Mehrens T, Thiele S, Suwelack B, Kempkes M, Hohage H: The beneficial effects of calcium channel blockers on long-term kidney transplant survival are independent of blood-pressure reduction. Clin Transplantation 2000, 14:257-26I.
Publish with BioMed Central and every scientist can read your work free of charge

"BioMed Central will be the most significant development for disseminating the results of biomedical research in our lifetime. "

Sir Paul Nurse, Cancer Research UK

Your research papers will be:

- available free of charge to the entire biomedical community

- peer reviewed and published immediately upon acceptance

- cited in PubMed and archived on PubMed Central

- yours - you keep the copyright
BioMedcentral 